\title{
Perspectives: Science in Rangeland Management
}

\author{
Clayton B. Marlow
}

$\mathrm{I}$ $\mathrm{t}$ is appropriate that we begin a new century and a new millennium with a discussion of the role of science in the protection and management of natural resources. The timeliness of our discussion takes on greater meaning when we consider the growing public concern that the scientific community cannot move rapidly enough to protect our dwindling natural resources from overexploitation or extinction. Aplet et al. (1992) pointed out that the American public has become "grimly aware" of the loss of biodiversity and is demanding that forests, rangelands and ocean resources be managed for more than market commodities. Until the last decade of the $20^{\text {th }}$ Century foresters, range conservationists and wildlife managers would have simply turned to Federal and land grant university researchers to develop new strategies for dealing with such a problem. However, there is increasing skepticism that anything positive can happen fast enough (Thomas and Salwasser 1989) and, more dramatically, that a scientific or technological solution will only spawn a dozen new problems of equal or greater magnitude (Stanley 1995). These conflicting social conditions give rise to two questions, what is to be done about the lack of public confidence in science based management and what role will the Society for Range Management play in regaining their confidence?

The bitter irony of society's disenchantment with the role of science in protecting and managing natural resources should not be overlooked because it was public concern over deforestation, loss of wildlife and range degradation that carried the philosophies of J.W. Powell and G. Pinchot into national policy at the beginning of the $20^{\text {th }}$ Century. More than anything else, it was the structured logic of scientific inquiry that led early conservationists and agency personnel like Powell and Pinchot, to believe that science based management would achieve conservation goals and protect the remaining natural resources from exploitation. Since its earliest beginnings it has been the structure and rules of scientific inquiry that kept both researchers and managers from reaching unsubstantiated or erroneous conclusions about the outcome of a project or treatment. In the Society for Range Management symposium, Science: Perspectives for Natural Resource Managers, Provenza (2000), Krueger and Kelley (2000) and Frasier (2000) emphasized the procedures that are followed in scientific inquiry. Without such rules to guide investigations the reader/practitioner is left with little more than product advertising. In fact, it is the very structure of scientific inquiry and reporting that gives researchers the opportunity to predict the outcome or response of an organism or ecosystem to a given set of conditions. Even though some land managers may be skeptical of the results from predictive models, researchers can use them to test new ideas and identify information gaps for further study. Predictive models can also be used by managers and program leaders to assess the risk of a given action or policy. However, a subtle but critical point often overlooked when selecting models and information for management application is how the information base that was used to create the model was developed. While the information used in ecological model development often comes from natural resource management and ecological literature, managers must be aware that all literature isn't always scientific or objective.

Krueger and Kelley (2000) found that only one third of the 1,500 articles on riparian and stream ecology could be considered scientific.

Even though most of the literature used to formulate natural resource models and action plans is generally described as scientific in nature, careful examination of the procedures used to develop that information indicates that much of it may not actually be scientific or objective. Joyce
(2000) has noted that the development of an objective and factual knowledge base is achieved through a process involving description, experimentation and quantification. Using this process as a criterion Krueger and Kelley (2000) found that only one third of the 1500 articles on riparian and stream ecology could be considered scientific. Over two thirds of the literature was either a synthesis of previous studies or what the Krueger and Kelley (2000) termed professional resource knowledge. This latter category was largely personal opinion gained through field observation. While there was probably no "malice afore thought" on the part of those publishing professional resource knowledge and synthesis papers, both categories of literature can have serious shortcomings.

Professional resource knowledge grows out of the experience and observations of managers and specialists in a variety of fields. Giving full credit to the power of observation and long term memory of field personnel the very real drawback to professional resource knowledge is that few of us have experience over broad portions of the landscape and, more importantly, live long enough to see all of the natural variation that can occur within an ecosystem. Thus, our understanding of the full range of ecosystem response is incomplete. Because professional resource knowledge is based on individual experience it would seem that such information would only be incorporated into models and management plans at the local level. However, a thorough review of the literature sources used in a West Coast National Forest Plan revealed that articles and reports based on professional resource knowledge had taken on the appearance of scientific literature by simply being cited in other publications (Allen-Diaz 2000). While the professional resource information may have been applicable in the local area it is unlikely that the same may hold true in other regions or under different climatic conditions or in different management scenarios. The scientific community has developed a procedure 
(Frasier 2000) to avoid such a situation by alerting its readers to the limitations of the information in a published paper. This procedure involves the review of the manuscript by qualified individuals out side the writer's agency or institution. Input from such reviews ensures that future readers can both understand the results of a study or model and be reasonably assured of the validity of the results. Professional resource knowledge based articles escape this scrutiny because they are often published as agency reports or included in general interest publications that require little or no outside review. Thus, use of professional resource knowledge based information, while instructive, may lead to unrealistic expectations on the part of managers and the general public. Furthermore, difficulties and controversy arise when professional resource knowledge articles gain the appearance of scientific credibility through citation in other reports or publications.

While it may appear that we could regain some level of credibility with the public at large and with other scientific and professional disciplines by clearly identifying when professional resource knowledge is and has been used in reports and publications, it is equally important to remember that the broad applicability of a scientific study is derived from the question or questions addressed by the study itself. Much of the distrust or impatience with the scientific community's ability to address environmental issues arises from two fundamental sources. First, the slow pace of inquiry required by the scientific process frustrates those concerned with the rapid loss of species and entire ecosystems. George Schaller, the well-published naturalist, has argued that the preservation of African and Asiatic wildlife is failing because scientists are reluctant to recommend any action "until more information can be gathered." Second, those dedicated to the preservation of a species or ecosystem are alarmed by the potential for bias in scientific studies. For example, environmental organizations, such as the Sierra Club, have warned range scientists that they are skeptical of results that seem to be "paid for" by a particular agency or interest group. This attitude is not confined to the environmental movement. Many livestock producers (Cady 2000) and a segment of gulf coast fisherman (Weeks et al. 1997) base their acceptance of science-based management on their perception of the scientist's background and experience. Thus, scientists who fail to win the acceptance of these natural resources users will have difficulty in getting their recommendations accepted, regardless of how thorough their research has been. While such issues appear to be directed at individual scientists, the broader scientific community faces the same condemnation because of the philosophical underpinning of western science.

The basic approach to problem solving used by American, Canadian, Mexican and European scientists has been, and continues to be based on reductionist methods. Any problem, whether it is the effect of livestock grazing on salmon habitat or how non-native plants invade apparently healthy native plant communities, will be reduced to its simplest parts for investigation. This enables the scientist to control all factors thought to effect the question so that he/she can ultimately identify cause and effect relationships. While extremely effective in developing factual and unbiased information the reductionist approach takes a prodigious amount of time to reach an answer and often as not the research indicates other areas where our knowledge is limited or lacking. Such results have created skepticism and distrust among environmental organizations and natural resource commodity groups because scientists appear to be "creating more work for themselves." In addition to this problem, a certain amount of bias can creep into a scientific study because of the manner in which the initial question to be investigated is developed.

A research question too broadly framed may fail to identify the subtle but powerful effects of a secondary plant metabolite on the competitive ability of other plants or the effect of a small shift in temperature on salmon egg survival. A question too narrowly focused may fail to identify the larger issue of coastal fishing pressure on salmon recruitment or the role of increased all terrain vehicle use on weed seed dispersal. Lastly, the question being researched may fail to meet the needs of the public at large because it is dictated by the agency or organization providing the research funding. In the United States the lion's share of research funds are awarded on a competitive basis and successful proposals tend to address concerns at the national level rather than those of local or regional importance. This drives research into arenas that may not have direct application to the problems a range conservationist is facing on the local district. Furthermore, funding guidelines and administrative rules rarely allow studies of sufficient duration to include the variety of climatic conditions that shape so many range and riparian ecosystems. Taken in total, these sideboards often limit the application of research results to such small areas that more research is needed to address the problem on a broader scale. When the "politics of science" are viewed in this light it should come as no surprise that land managers and the public have grown skeptical of scientists' ability to provide solutions for difficult environmental issues. If this skepticism is ignored by the research community, including members of the Society for Range Management, through "academic snobbery" (Thomas and Salwasser 1989), we as a Nation stand to lose a great deal. As greater and greater demands are placed on the world's natural resources by our insatiable desire for bigger homes, faster cars and more exotic vacations the creation of more roadless areas and national parks will be little more than a band-aid. Objective, reliable information must be used to create both interim management policies and long-term educational programs if we are to achieve a balance between human demands and the sustainability of the world's ecosystems.

To regain the trust and confidence of land management personnel and the general public in science-based management we as a professional society and as individuals must re-examine our own attitude 
about the role of science in rangeland management. It is critical that resource managers stop and ask if the professional resource knowledge we've gained over the years is as infallible and unchangeable as we'd like to believe. Those concerned with the preservation of a species or an ecosystem must honestly appraise their expectations, are the population levels or acreages desired based in reality or a dream of "what it was like before the white man got here"? The scientific community must shake of its elitism and allow discussion of policy, economics and nature reserve design in professional publications like the Journal of Range Management, Forestry Science, Journal of Forestry and the Journal of Wildlife Management (Aplet et al 1992). Hopefully, through this introspection each of us will come to that same realization that Plato's character Socrates shares in the Apology; "Each of them believed himself to be extremely wise in matters of the greatest importance because he was skillful in his own art: and this presump tion of theirs obscured their real wis dom." Like the Athenians of Plato's time we may have "obscured our real wisdom" by becoming lackadaisical in what we call scientific based management and by being too confident in what we think we know about or what we can expect from nature.

If we are realistic about what we truly know about nature, we must admit that natural systems are both temporally and spatially dynamic. Provenza (2000) has noted that the dynamic complexity of nature makes it difficult to predict outcomes or reactions across space and time and, yet, managers and scientists alike proceed with programs and modeling as if we can fully predict everything that can and will happen. This occurs in spite of evidence that many of the changes in nature take place at such a small scale and over such a long period of time that we humans rarely notice them. Nonetheless it is these small changes which shape great rivers and mountains and the very genetic code of our bodies. If this principle of steady, incremental change was not true then our pre-occupation with plant community succession and species evolution has been a flirtation rather than a science. I will suggest that our "real wisdom" about nature is that change is inevitable and that we as managers and scientists must be willing to accept the fact that with new information and experience some time honored principles and management practices may no longer be valid. Thus, each of us has a responsibility as a member of the Society for Range Management and as a "citizen of the world" to regularly re-examine what we think we know and to seek out the best of science and technology to fill in our knowledge gaps. We should never reach the point were we believe we know all there is to know or that a single management action will always conserve a resource. We must also be aware of the evolution of society. Because societies change and evolve the type and level of demand they place on a resource or ecosystem will also change. Restrictive game laws and conservation practices on the Northern Great Plains were unnecessary when there was no market for beaver pelts or buffalo robes.

\section{It is critical that resource man-} agers stop and ask if the professional resource knowledge we've gained over the years is as infallible and unchangeable as we' $d$ like to believe.

In closing, I want to emphasize two points that ran through all the presentations in the Science: Perspectives for Natural Resource Managers symposium. First, science is observation, development of concepts, testing of those concepts and thorough review of pre-published manuscripts by qualified reviewers. Simply being cited in a report or publication does not make a body of work science and therefore valid. Second, because natural systems are constantly changing we as managers, policy makers and the general public must be committed to re-examining our own knowledge base and "landscape" expectations on a regular basis. Things that once appeared to be facts may be found to be biased or inadequate today. Thus, many of the conflicts over rangeland use may be the result of out-dated and unrealistic expectations of what rangelands can provide. Carl Taylor, author and rural economist, once stated that conservation was both a social and a moral problem and as such could not be addressed by science alone (Taylor 1951). Even though we have concentrated on the scientific side of the equation all morning, I would like to conclude this session with a quote from Dr. Taylor, "The need is not only for scientific knowledge but conscience, not only for reason but for sentiment." To this I would add, science can only tell us what can be done, we, alone, must decide if it should be done.

\section{References}

Allen-Diaz, B.H. and K. W. Tate. 2000. Science, dogma, or fact: Grazing in the Sierra Nevada. Annual Meeting Society for Range Management. Invited Presentation. Boise, Idaho.

Aplet, G.H., R.D. Laven and P.L. Fiedler. 1992. The relevance of conservation biology to natural resource management. J. Conserv. Biol. 6:298-300.

Cady, C. 2000. How ranchers use science in land management. Abs. of Papers. $53^{\text {rd }}$ Annual Meeting Society for Range Management. Boise, Idaho. p. 22.

Frasier, G.W. 2000. Describing and evaluating peer review processes for natural resources literature. Abs. of Papers. 53 $3^{\text {rd }}$ Annual Meeting Society for Range Management. Boise, Idaho. p. 22

Joyce, L. 2000. How models use and produce science. Abs. of Papers. 53 ${ }^{\text {rd }}$ Annual Meeting Society for Range Management. Boise, Idaho. p. 22-23.

Krueger, W.C. and C. E. Kelley. 2000. Describing and evaluating literature used by riparian zone managers. Abs. of Papers. 53 ${ }^{\text {rd }}$ Annual Meeting Society for Range Management. Boise, Idaho. p. 23.

Provenza, F. 2000. Science, myth and the management of natural resources. Abs.of Papers. 53 ${ }^{\text {rd }}$ Annual Meeting Society for Range Management. Boise, Idaho. p. 23.

Stanlely, T.R. 1995. Ecosystem management and the arrogance of humanism. J. of Conserv. Biol. 9:255-262.

Taylor, C.C. 1951. Conservation: a social and moral problem. J. Soil and Water Conserv. 6(1):7-14.

Thomas, J.W. and H. Salwasser. 1989. Bringing conservation biology into a position of influence in natural resource management. J. Conserv. Biol. 3:123-127.

Weeks, P. and J.M. Packard. 1997. Acceptance of scientific management by natural resource dependent communities. J. Conserv. Biol. 11:236-245.

Author is an Associate Professor with the Animal and Range Sciences Department, Montana State University, Bozeman, Montana 